\title{
Ultrasound-Assisted Extraction of Antimicrobial Compounds from Thymus daenensis and Silybum marianum and Investigation of its in Presence and Without of Natural Silver Nanoparticles
}

\author{
Safarpoor $\mathbf{M}^{1^{\star}}$, Yousefinejad $\mathbf{M}^{2}$, Ghaedi $\mathbf{M}^{3}$, Zare Khafri $\mathbf{H}^{1}$, Asfaram $\mathbf{A}^{1}$, Bagherinasab $\mathbf{M}^{3}$ and Kocheki Shahmokhtar $\mathbf{M}^{1}$ \\ ${ }^{1}$ Department of Chemistry, Yasouj University, Yasouj, Iran \\ ${ }^{2}$ Department of Biology, Yasouj University, Yasouj, Iran \\ ${ }^{3}$ Department of Animal Science, Kermanshah University, Kermanshah, Iran
}

*Corresponding author: Safarpoor M, Department of Chemistry, Yasouj University, Yasouj, Iran, Tel: +98-741-2223048; E-mail: safarpoormohamad@yahoo.com Received: August 12, 2017; Accepted: August 21, 2017; Published: August 30, 2017

Copyright: ( 2017 Safarpoor M. This is an open-access article distributed under the terms of the Creative Commons Attribution License, which permits unrestricted use, distribution, and reproduction in any medium, provided the original author and source are credited.

\begin{abstract}
The present study is devoted to construction of new antibacterial and anti-fungal agent based on combination of in situ synthesized silver nanoparticles with plants extract, while through a green synthesis Ag-NPs were synthesized at room temperature using Rosmarinus officinalis leaf extract. In this study, hydroalcoholic extracts have been used for with Ultrasonic method. Ultrasonication has recently received attention as a novel bioprocessing tool for process intensification in many areas of downstream processing. Antimicrobial activities of $T$. daenensis and $S$. marianum extracts in the presence and absence of Ag-NPs was investigated at concentrations between 12.5-50 $\mathrm{mg} / \mathrm{mL}$ against Staphylococcus aureus (Gram-positive organisms), Escherichia coli (Gram-negative organisms), and fungal strains were Aspergillus oryzae, Candida albicans. Antimicrobial activity determined using agar disc diffusion method reveal that activities of Ag-NPs/T. daenensis were superior to Ag-NPs/S. marianum and extracts $(T$. daenensis and S. marianum). Medicinal plant extracts is able to synthesis the Ag-NPs as an eco-friendly and inexpensive method in large scale. The extract/Ag-NPs has good antibacterial and antifungal activity that candidate them as potential tool to combat against rapidly increasing antibiotic resistance. Antioxidant content of the extracts was also determined and demonstrated the highest antioxidant activities associated with the shoot of Thymusdaenensis (Total phenolic content: $198.71 \pm 1.50 \mathrm{mg}$ gallic acid equivalents/g of dried extract, DPPH: 48.80 $\pm 0.59 \%$ inhibition and Total Flavonoid Content: $172.42 \pm 1.43 \mathrm{mg}$ rutin equivalents (RuE)/g of dried extract).
\end{abstract}

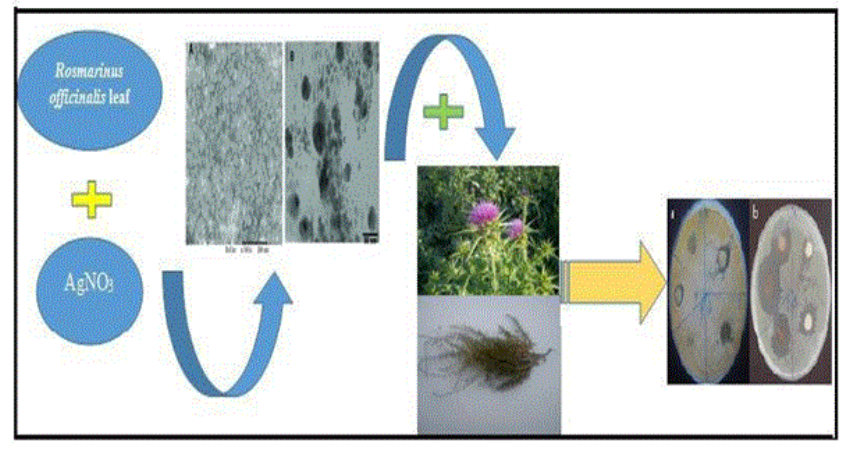

Keywords: Ultrasonic-assisted extraction; Green synthesis; Antimicrobial; Disc diffusion; Antioxidant

\section{Introduction}

Nano-structure material as important tool in health and medicine [1] and represent improvement in properties in comparison to bulk materials that may be related to change in their size distribution and morphology. Higher surface area to volume ratio is proportional to decrease in the size of the particles [2-4] and their simple synthesis by biosynthesis lead to outcomes viz. clean and nontoxic chemicals, environmentally friendly solvents and renewable materials [5]. Plant extracts is safe and green media for synthesis of nanoparticles in comparison to chemical and physical methods in term of cost- effectiveness, environment friendly, single-step and easy synthesis in large-scale [6]. The size, morphology, stability and physicochemical properties of metallic based nanoparticles depend on the experimental conditions [7-9] and in this regard more attention developed to AgNPs as inhibitory and antibacterial materials. Resistance of antimicrobial agents to pathogenic bacteria. A major challenge for health care industry that encourage researchers to overcome this limitation [10-20]. Plants source usability in medicine was recognized as main or complimentary medicinal products [21-23]. Plants of labiate family traditionally applied for treatment of exhaustion, weakness, depression, memory enhancement, circulation improvement, strengthening of fragile blood vessels [24] inflammation, infection [25] indigestion and gastritis [26]. Presence of antioxidant [27] anti-inflammatory [28] anti-allergic [29] anti- 
Citation: Safarpoor M, Yousefinejad M, Ghaedi M, Zare Khafri H, Asfaram A, et al. (2017) Ultrasound-Assisted Extraction of Antimicrobial Compounds from Thymus daenensis and Silybum marianum and Investigation of its in Presence and Without of Natural Silver Nanoparticles. Nat Prod Chem Res 5: 289. doi:10.4172/2329-6836.1000289

Page 2 of 9

depression [30] anti-hyperglycemic [31] and antimicrobial [32-34] agent in plant extracts candidate them for overcoming more health problems. Thymus plant leaves and flower parts has good talent to applied for tonic and herbal tea, antiseptic, antitussive and carminative as well as treating cold [35-37]. Thymus oil and extracts applied in pharmaceutical, cosmetic and perfume industry besides flavoring and food preservation [38]. Silybum marianum cancer chemoprevention and hepatoprotection has high and brilliant role in treatment on of Phenolic compounds in aromatic extract and plants are one of the defensive mechanisms against bacterial agents, herbivore and insects [39-46]. Plants metabolites and/or constituent such as tannins, terpenoids, alkaloids, flavonoids, glycosides has more potential to be antimicrobial agent [47-50] and always the antimicrobial property of medicinal extract plants in presence and without of natural silver nanoparticles are significantly differ. In this research, T. daenensis and $S$. marianum absence of extracts combination with silver nanoparticles (Ag-NPs) in this media extensively was prepared and subsequently, used against some pathogenic bacteria and fungi to detect new sources of antimicrobial agents.

\section{Materials and Methods}

\section{Chemicals, reagents and plant source}

All reagents were of analytical grade and obtained from Merck, Dermasdat, Germany. The fresh and healthy plants of $T$. daenensis, $S$. marianum and $R$. officinalis were collected in June year 2013 from various areas of Yasouj district, Iran and subsequently were identified in photochemistry Lab in Yasouj University.

\section{Extraction}

Ultrasound-Assisted Extraction (UAE): Medicinal plants (Thymus daenensis and Silybum marianum) firstly washed thoroughly to remove impurities, shade dried and then ground to fine powder. Five grams $(5.0 \mathrm{~g})$ of Medicinal plants powder were placed in a capper tube and mixed with ethanol. The extraction process was performed with the ultrasonic device (JAC Ultrasonic 2010P, Jinwoo Engineering Co., Ltd., Hwasung, Gyeonggi, Korea) equipped with a digital timer and a temperature controller, the solvent used in the extraction was ethanol solution. The device was operated at a frequency of $40 \mathrm{kHz}$, an ultrasonic input power of $250 \mathrm{~W}$. After ultrasonic extraction, the sample was centrifuged at $4000 \mathrm{rpm}$ for $15 \mathrm{~min}$, and the supernatant was collected. When the ultrasonic extraction was completed, the extracts were immediately cooled on ice to room temperature, filtered using a $5-\mathrm{mL}$ syringe fitted with a $0.45 \mu \mathrm{m}$ cellulose syringe filter (Phenomenex Australia Pty. Ltd., Lane Cove, Australia) Ultrasonication is a branch of acoustics that can be applied to solids, liquids and gases at frequencies above the human hearing range [51]. Ultrasonication generates an enormous interfacial area between the oil and alcohol due to micro turbulence leading to the formation of fine emulsions [52].

\section{Preparation of Rosmarinus officinalis extract for synthesis of Ag-NPs}

$R$. officinalis leaves were collected, chopped and dried for two days at room temperature. Dried leaves were washed thoroughly with distilled water and aqueous extract was prepared. Prepared extract was centrifuged and filtered through Whatman 41 filter paper to obtain clear solution. The filtrate was used immediately for Ag-NPs synthesis which served as reducing and stabilizing agent. $50 \mathrm{~mL}$ of $1 \mathrm{mM} \mathrm{AgNO}_{3}$ was added to $25 \mathrm{~mL}$ of aqueous extract of R. officinalis and mixed thoroughly via magnetic stirrer. The reaction mixture was then shaken to mixed completely and allowed to settle at room temperature. The color change to yellow confirm the formation of silver nanoparticles.

\section{Purification of Ag-NPs}

To separate unreacted components of reaction mixture was removed from the synthesized Ag-NPs the mixture was centrifuged [53] at $10000 \mathrm{rpm}$ for $25 \mathrm{~min}$ and washed for three times using deionized water. Dried powder of the silver nanoparticles was obtained by freezedrying. Ultra-centrifugation techniques were used to separated nanoparticles based on their size. Apart from centrifugation, chromatographic based separations such as HPLC and ion exchange chromatography was also utilized for separating nanoparticles from reaction mixture [54]. Separation of nanoparticle is a vital step in synthesis of nanoparticles from its reaction [55].

\section{Characterization of synthesized nanoparticles}

UV-Vis spectrometer (Perkin Elmer Lambda 25) was used to record absorbance in the range of $200-800 \mathrm{~nm}$ and also monitor the rate of Ag-NPs formation. $250 \mathrm{~mL}$ of each sample was diluted with $2 \mathrm{~mL}$ deionized water and sonicated for $15 \mathrm{~min}$. The $\mathrm{pH}$ of stock solution (1 $\mathrm{mg} \mathrm{L}^{-1}$ ) was adjusted to 11.0 before scanning in quartz cuvettes with deionized water as reference. Factors such as temperature, $\mathrm{pH}$, concentration of leaf extracts and concentration of $\mathrm{AgNO}_{3}$ influences on the formation of Ag-NPs in the reaction mixture were examined by UV-Vis absorbance spectroscopy. The UV-Vis spectra of Ag-NPs which at RT dispersed in distilled water via $30 \mathrm{~min}$ of sonication and subsequently centrifuged at speed of $9000 \mathrm{rpm}$ for $30 \mathrm{~min}$ was recorded. The pure Ag-NPs was prepared following removal of unbound ligand. X-ray diffraction (XRD) spectra were obtained by an automated Philips X'Pert X-ray diffractometer with $\mathrm{Cu}$ Radiation (40 $\mathrm{kV}$ and $30 \mathrm{~mA}$ ) for $2 \theta$ values over range of $30^{\circ} \mathrm{C}-80^{\circ} \mathrm{C}$. Scanning electron microscope (SEM: Hitachi S-4160) under an acceleration voltage of $30 \mathrm{kV}$. TEM analysis was recorded using TEM JEOL at 300 $\mathrm{kV}$.

\section{Biological activity}

Antimicrobial assays: The well-diffusion method was used to study the antibacterial activity. All the glassware, media, and reagents used were sterilized in an autoclave at $121^{\circ} \mathrm{C}, 103 \mathrm{kPa}$ of pressure for $21 \mathrm{~min}$. Staphylococcus aureus (ATCC 25293), Escherichia coli (ATCC 33218) were used as model test strains for Gram-positive and Gram-negative bacteria, respectively. All the microbial cultures were adjusted to 0.5 McFarland standard, which are visually comparable to a microbial suspension of approximately $1.5 \times 108 \mathrm{CFU} / \mathrm{mL}$ [56]. $100 \mu \mathrm{L}$ of fresh bacterial culture was gently spread on the agar surface [57]. The bacterial concentration utilized was of $1.5 \times 108 \mathrm{CFU} / \mathrm{mL} .6 \mathrm{~mm}$ diameter filter paper disc, impregnated with $20 \mathrm{~mL}$ dose of each compounds. Using sterile disc ( $6 \mathrm{~mm}$ diameter) were bored into the seeded agar plates and these were loaded with $50 \mathrm{~mL}$ volume with concentration of 50,25 and $12.5 \mathrm{mg} \mathrm{L}^{-1}$ of each compound reconstituted in dimethyl sulfoxide (DMSO). All the plates were incubated at $37^{\circ} \mathrm{C}$ for $24 \mathrm{~h}$. Antibacterial activity of all the complexes was evaluated by measuring the diameter of zone of inhibition in $\mathrm{mm}$ (Table 1) and all investigation were undertaken using dimethyl sulfoxide (DMSO) as solvent. Amoxicillin, Cephalexin and Penicillin was used as controlled antibacterial agents and their results for 
Citation: Safarpoor M, Yousefinejad M, Ghaedi M, Zare Khafri H, Asfaram A, et al. (2017) Ultrasound-Assisted Extraction of Antimicrobial Compounds from Thymus daenensis and Silybum marianum and Investigation of its in Presence and Without of Natural Silver Nanoparticles. Nat Prod Chem Res 5: 289. doi:10.4172/2329-6836.1000289

Page 3 of 9

antibacterial activity was compared with under study material in Table 2 .

\begin{tabular}{|l|l|l|l|l|l|l|}
\hline \multirow{2}{*}{ Compound } & \multicolumn{4}{l|}{ Gram-positive } & \multicolumn{4}{l}{ Gram-negative } \\
\cline { 2 - 7 } & \multicolumn{2}{|l|}{ S. aureus } & \multicolumn{4}{l}{ E. coli } \\
\hline & 12.5 & 25 & 50 & 12.5 & 25 & 50 \\
\hline T. daenensis & 14.00 & 15.70 & 17.62 & 13.40 & 15.00 & 15.22 \\
\hline S. marianum & 9.70 & 10.50 & 12.30 & 8.50 & 10.10 & 11.38 \\
\hline
\end{tabular}

\begin{tabular}{|l|l|l|l|l|l|l|}
\hline T. daenensis-Ag & 14.40 & 17.40 & 18.00 & 13.40 & 16.00 & 16.20 \\
\hline S. marianum-Ag & 9.90 & 12.30 & 19.00 & 9.70 & 11.38 & 11.60 \\
\hline S. marianum & 9.70 & 10.50 & 12.30 & 8.50 & 10.10 & 11.38 \\
\hline
\end{tabular}

Table 1: Antibacterial activity of compounds in dose of $(12.5,25$ and 50 $\left.\mathrm{mg} \mathrm{L}^{-1}\right)$. All tests were performed twice and all data are the mean of two measurements.

\begin{tabular}{|c|c|c|c|c|c|c|}
\hline Antibiotic drugs & $\begin{array}{l}\text { Bacillus } \\
\text { subtilis }\end{array}$ & Staphylococcus aureous & $\begin{array}{l}\text { Pseudomonas } \\
\text { aeroginosa }\end{array}$ & Escherichia coli & $\begin{array}{l}\text { Candida } \\
\text { albicans }\end{array}$ & Aspergillus oryzae \\
\hline $\begin{array}{l}\text { Amphotericin } \quad B \quad(0.03 \\
\mathrm{mg} / \mathrm{disc})\end{array}$ & - & - & - & - & 28.10 & 37.6 \\
\hline $\begin{array}{l}\text { Amoxicillin }(0.025 \mathrm{mg} / \\
\text { disc) }\end{array}$ & 28.10 & 41.60 & - & 20.80 & - & - \\
\hline Penicillin (0.01 mg/disc) & 30.50 & 47.60 & - & 9.70 & - & - \\
\hline $\begin{array}{l}\text { Cephalexin } \quad(0.03 \mathrm{mg} / \\
\text { disc) }\end{array}$ & 37.60 & 41.60 & - & 22.56 & - & - \\
\hline
\end{tabular}

Table 2: Diameter of zone of inhibition ( $\mathrm{mm})$ of antibiotic drugs.

Antifungal screening by disc diffusion method: Aspergillus oryzae (PTCC 5164, A. oryzae) and Candida albicans (ATCC 10231, C. albicans) were used as mode for determinations of anti-fungal activities of extracts of $S$. marianum and $T$. daenensis by the disc diffusion method on the surface of Sabouraud Dextrose Agar inoculated with $1.010^{5}(\mathrm{CFU} / \mathrm{mL})$ of spore suspension of fungi. The petri plates cultured with Aspergillus oryzae were incubated at $30^{\circ} \mathrm{C}$ for 24-48 h while the plates cultured with $C$. albicans were incubated at $32^{\circ} \mathrm{C}$ for $24-48 \mathrm{~h}$. The discs impregnated with compounds solution (solubilized in 5\% w/v DMSO) of compounds doses (12.5, 25 and 50 $\mathrm{mg} / \mathrm{disc}$ ) were dispensed at different positions on the agar plate [57]. At end of incubation period, antifungal activities of extracts were determined in term of inhibition zone diameter value. Antifungal activities of control drug Amphotericin B (0.03 mg/disc) is shown in Table 3.

\begin{tabular}{|l|l|l|l|l|l|l|}
\hline \multirow{2}{*}{ Compound } & \multicolumn{3}{|c|}{ Candida albicans } & \multicolumn{3}{l|}{ Aspergillus oryzae } \\
\cline { 2 - 7 } & 12.5 & 25 & 50 & 12.5 & 25 & 50 \\
\hline T. daenensis & 7.50 & 8.90 & 11.00 & 7.20 & 7.80 & 10.64 \\
\hline S. marianum & 6.90 & 7.00 & 7.68 & 6.94 & 7.00 & 7.44 \\
\hline T. daenensis-Ag & 8.12 & 9.38 & 11.20 & 8.00 & 8.10 & 10.70 \\
\hline S. marianum-Ag & 7.20 & 7.50 & 8.12 & 7.10 & 7.22 & 7.68 \\
\hline
\end{tabular}

Table 3: Antifungal activity of compounds in dose of $(12.5,25$ and 50 $\left.\mu \mathrm{g} \mathrm{L}^{-1}\right)$. All tests were performed twice and all data are the mean of two measurements.

\section{Determination of total phenolic content}

The total phenolic content (TPC) of the T.daenensis and S.marianum extracts was determined by using the Folin-Ciocalteu reagent [58]. $100 \mu \mathrm{l}$ of the diluted ethanolic extracts containing $500 \mu \mathrm{g}$ extract was mixed separately with $(500 \mu \mathrm{l})$ Folin-Ciocalteu reagent and diluted with distilled water and $0.4 \mathrm{ml}$ of $(7.5 \% \mathrm{w} / \mathrm{v})$ sodium carbonate solution $\left(\mathrm{Na}_{2} \mathrm{CO}_{3}\right)$. The solution was mixed and allowed to stand for 1 hour at room temperature. Gallic acid solution (from 25 to $300 \mu \mathrm{g} / \mathrm{ml}$ ) was used as a standard reagent. Finally, the absorbance was measured at $765 \mathrm{~nm}$ using a UV-Vis spectrophotometer. A calibration curve was prepared by using of standard solutions of gallic acid. The results were expressed as mg gallic acid equivalents (GAE)/gr of dried extract.

\section{Determination of total flavonoid}

Total flavonoid content of extracts was also determined [59]. $1 \mathrm{mg}$ of extracts were diluted with $1000 \mu \mathrm{l}$ of distilled water and $100 \mu \mathrm{l}$ of $5 \%$ $\mathrm{NaNO}_{2}$ solution were added. The mixture was kept at room temperature for $5 \mathrm{~min}$ and then, $200 \mu \mathrm{l}$ of $10 \% \mathrm{AlCl}_{3}$ were added to it. This mixture was incubated at room temperature for a 6 min then $1 \mathrm{ml}$ of $1 \mathrm{M} \mathrm{NaOH}$ was added to the mixture. The solution absorbance at $510 \mathrm{~nm}$ was measured with a UV-Vis spectrophotometer. The concentration of the flavonoid compounds was calculated by using of the equation that obtained from the rutin $(50-500 \mu \mathrm{g} / \mathrm{ml})$ calibration curve.

\section{Scavenging effect on 2, 2-diphenyl-1- picrylhydrazyl (DPPH)}

Free radical scavenging activity was estimated by 2,2-diphenyl-1picryl-hydrazyl (DPPH) assay by using of Von Gadow method with some modifications60. $2.4 \mathrm{ml}$ of DPPH radical solution $(24 \mu \mathrm{g} / \mathrm{ml})$ prepared in $70 \%$ aqueous ethanol. The reaction mixture contained 100 $\mu \mathrm{l}$ of test extracts and $1 \mathrm{ml}$ of methanolic solution of $(24 \mu \mathrm{g} / \mathrm{ml})$ of $\mathrm{DPPH}$ radical. The mixture was then shaken vigorously and incubated at $37^{\circ} \mathrm{C}$ for $10 \mathrm{~min}$. The absorbance was measured at $517 \mathrm{~nm}$ by using by trolex solutions $(100-1000 \mu \mathrm{g} / \mathrm{ml})$ as a standard. Lower absorbance of the reaction mixture indicated higher free radical scavenging activity which was calculated using the following equation: DPPH scavenging effects $(\%)=100 \times(\mathrm{Ac}-\mathrm{As}) /(\mathrm{Ac})$ where $\mathrm{Ac}$ is the 
Citation: Safarpoor M, Yousefinejad M, Ghaedi M, Zare Khafri H, Asfaram A, et al. (2017) Ultrasound-Assisted Extraction of Antimicrobial Compounds from Thymus daenensis and Silybum marianum and Investigation of its in Presence and Without of Natural Silver Nanoparticles. Nat Prod Chem Res 5: 289. doi:10.4172/2329-6836.1000289

Page 4 of 9

absorbance of the control reaction and as is the absorbance of reaction mixture containing DPPH and extract at $517 \mathrm{~nm}$.

\section{FT-IR Spectrum analysis of extracts}

FT-IR (JASCO FT/IR-460 System in the $400-4000 \mathrm{~cm}^{-1}$, Japan) relies on the fact that the most molecules absorb light in the infra-red region of electromagnetic spectrum. This absorption corresponds specifically to the bonds present in the molecule. The frequency ranges are measured as wave numbers typically over the range $4000-400 \mathrm{~cm}^{-1}$. Figure 1 shows the FT-IR peaks of dried extracts. Hydroxyl group in alcoholic and phenolic compound which is supported by the presence of a strong peaks. The absorbance bands are associated with the stretch vibrations of alkyl $\mathrm{C}-\mathrm{C}$, conjugated $\mathrm{C}-\mathrm{C}$ with a benzene ring, bending in plate of $\mathrm{C}-\mathrm{O}-\mathrm{H}, \mathrm{C}-\mathrm{O}$ stretch and bending out of plate $\mathrm{C}-\mathrm{H}$ in saturated tertiary or secondary highly symmetric alcohol in extracts, respectively.

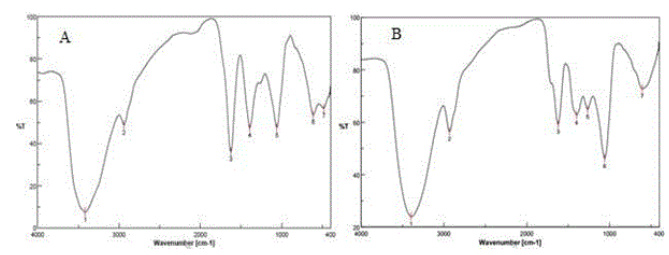

Figure 1: Fourier transform infrared absorption spectra of dried extracts. A) T. daenensis B) S. marianum.

\section{Results and Discussion}

\section{Characterization of Ag-NPs}

Figure 2 shows the FT-IR peaks of dried $R$. officinalis leaf extract. Typical peak of hydroxyl groups of phenolic compounds indicated by at $3397 \mathrm{~cm}^{-1}$. The peaks at $2933 \mathrm{~cm}^{-1}, 1621 \mathrm{~cm}^{-1}, 1400 \mathrm{~cm}^{-1}, 1265 \mathrm{~cm}^{-1}$, $1060 \mathrm{~cm}^{-1}$ and $605 \mathrm{~cm}^{-1}$ are associated with stretching vibrations of alkyl C-C, conjugated C-C of benzenoid rings, bending in plate of $\mathrm{C}$ $\mathrm{O}-\mathrm{H}, \mathrm{C}-\mathrm{O}$ stretch and bending out of plane $\mathrm{C}-\mathrm{H}$, respectively of saturated, tertiary and secondary symmetric hydroxylic groups of $R$. officinalis leaf extract.

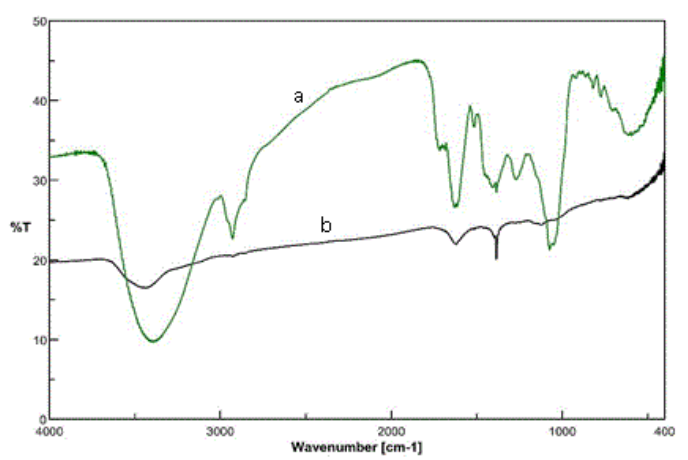

Figure 2: FT-IR spectra of (a) dried Rosmarinus officinalis leaf extract and (b) synthesized Ag-NP's.
The XRD pattern of Ag-NPs Figure 3a represent distinguished diffraction peaks at $2 \theta$ of $38.5^{\circ}(111), 44.1^{\circ} \mathrm{C}(200), 64.5^{\circ} \mathrm{C}\left(\begin{array}{lll}2 & 2 & 0\end{array}\right)$ and $77.3^{\circ} \mathrm{C}$ (311) which strongly indicates the face-centered cubic (FCC) crystalline structure of Ag-NPs. According to Debye sheerer and half width of XRD patterns, average particle size of Ag-NPs was calculated around $33 \mathrm{~nm}$ and intense reflection at (111) compare to other peaks support the growth direction of nanocrystals. SEM image of dropcoated film of the Ag-NPs synthesized with R. officinalis leaf extract (Figure $3 \mathrm{~b}$ ) reveal spherical and uniformly nano-size Ag-NPs. TEM image (Figure 3c) also confirms the spherical shape of AgNPs which are of FCC oriented with aggregation, while its size range of $10-33 \mathrm{~nm}$ and average value is around $29 \mathrm{~nm}$ with good agreement with XRD data.

Reduction of $\mathrm{Ag}^{+}$ions to $\mathrm{Ag}$ (in $1 \mathrm{mM}$ solution of $\mathrm{AgNO}_{3}$ ) was traced by $R$. officinalis leaf extract absorption spectra as function of time reveal. (Figure $4 \mathrm{a}$ ) shows the clear solution of $R$. officinalis leaf extract and Figure $4 \mathrm{~b}$ shows the yellowish brown coloured Ag-NP's colloidal solution. Maximum absorbance was observed at $450 \mathrm{~nm}$ which is related to formation of Ag-NPs (Figure 3d) reveal that Plasmon resonance (SPR) of conducting electrons of Ag-NPs. This unique peak is due to surface $\mathrm{R}$. officinalis. The nucleation process is acceleration slowly and reaction took about $4.5 \mathrm{~h}$ to complete, while no significant Ag-NPs formation was seen at $30 \mathrm{~min}$. The rate of formation increases rapidly toward $\mathrm{t}=270 \mathrm{~min}$ and confirmed by adsorption platue at further time. The Ag-NPs synthesis was completed in $4.5 \mathrm{~h}$ and was very stable during further experiments. The XRD analysis was used to study the crystalline nature of green synthesized Ag-NPs.

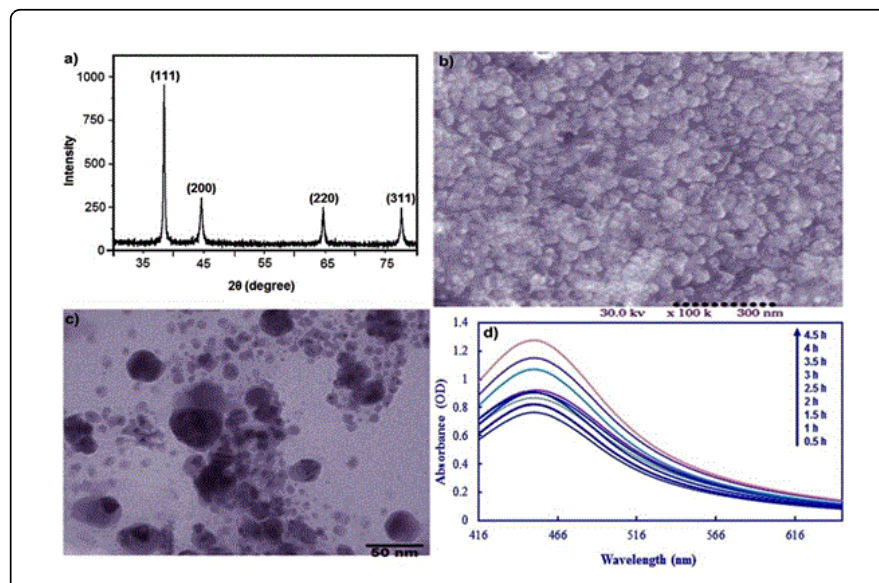

Figure 3: a) XRD pattern of green-synthesized silver nanoparticles by using leaf of R.officinalis, b) SEM image of Ag nanoparticles formed by R.officinalis, c) TEM image and d) Ultraviolet-visible spectra for formation of Ag-NP are as a function of time. 
Citation: Safarpoor M, Yousefinejad M, Ghaedi M, Zare Khafri H, Asfaram A, et al. (2017) Ultrasound-Assisted Extraction of Antimicrobial Compounds from Thymus daenensis and Silybum marianum and Investigation of its in Presence and Without of Natural Silver Nanoparticles. Nat Prod Chem Res 5: 289. doi:10.4172/2329-6836.1000289

Page 5 of 9
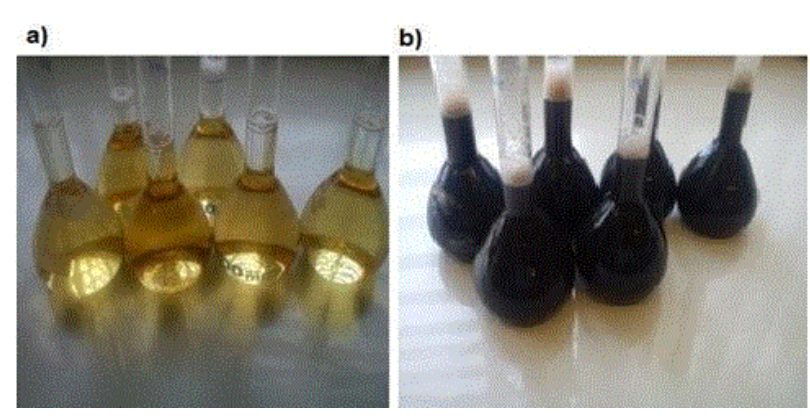

Figure 4: (a) Clear solution of R.officinalis leaf extract, (b) Ag-NP's after reaction of $\mathrm{AgNO}_{3}$ with R.officinalis leaf extract.

\section{Biological activity}

Antimicrobial assays (in vitro): The in vitro antibacterial activity of Ag-NPs/extracts and T. daenensis and $S$. marianum extracts were evaluated based on the growth inhibition zone [mm; Figures 5-13; Tables 1-3]. Maximum zone of inhibition in concentrations $(12.5,25$ and $50 \mathrm{mg} / \mathrm{disc})$ was found to be $(14.40,17.4,19) \mathrm{mm}$ in Staphylococcus aureus (Table 1). The images of zone of inhibition in discs are shown in Figure 14. The solvent used for the preparation of compound solutions (DMSO) did not show inhibition against the tested organisms [as a negative control]. Extracts of T. daenensis and $S$. marianum exhibited significant activity against $S$. aureus and moderate activity against E. coli against. Finally, inhibitory effects of Ag-NPs/ extracts confirm that the best effects and significant activity against $S$. aureus and $E$. coli even at low concentration [12.5 and $25 \mathrm{mg} / \mathrm{mL}]$. Increasing the concentration of Ag-NPs /extracts solution to 50 $\mathrm{mg} / \mathrm{mL}$ is associated with significant activity against $S$. aureus and $E$. coli, Silybum-Ag showed strong activity against $T$. daenensis-Ag at 50 $\mathrm{mg} / \mathrm{mL}$ [Figures 6 and 3]. The Ag-NPs/ T. daenensis had the best effects and showed significant activity against pathogen bacteria even at low concentration [12.5-25 mg/mL] [ Figures 5,6,8-11]. Compounds $T$. daenensis, $S$. marianum and Ag-NPs/extracts was active against $C$. albicans at $12.50,25,50 \mathrm{mg} / \mathrm{mL}$ concentration that have better antifungal activity against than A.oryzae, T.daenensis and Ag-NPs/ Silybum, better activity against Silybum marianum extract but was weak against Ag-NPs/ Thymus and T.daenensis extract [Figures 5-14].

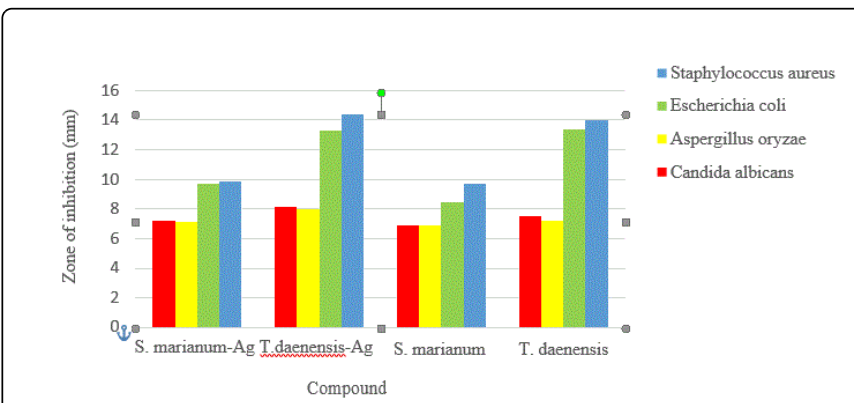

Figure 5: Antimicrobial activity of extracts in presence and without of Ag-NPs [12.5 mg/mL].

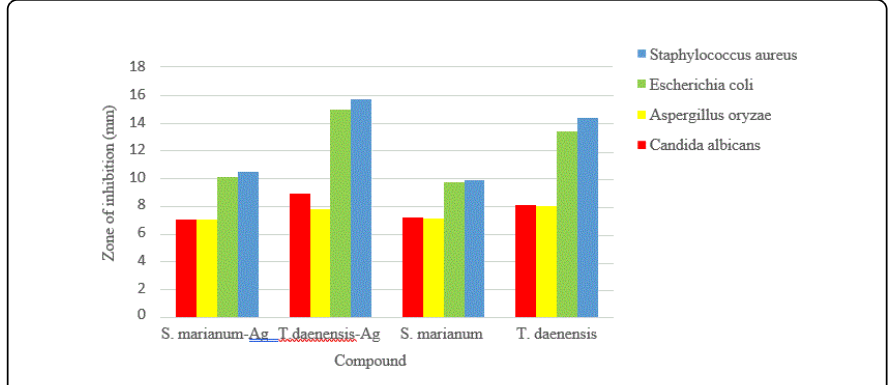

Figure 6: Antimicrobial activity of extracts in presence and without of Ag-NPs. [25 mg/mL].

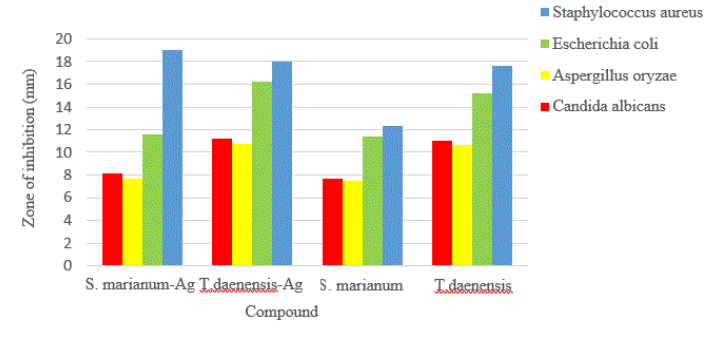

Figure 7: Antimicrobial activity of extracts in presence and without of Ag-NPs [ $50 \mathrm{mg} / \mathrm{mL}$ ].

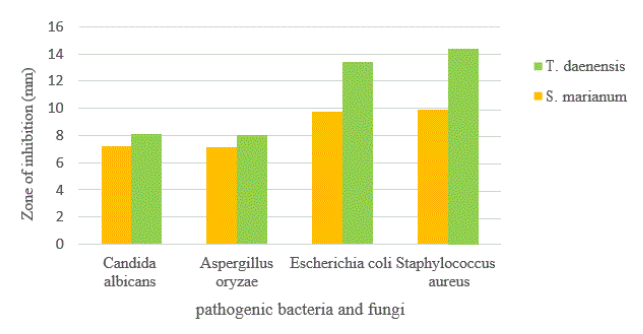

Figure 8: Antimicrobial activity of extracts in presence of natural silver nanoparticles $[12.5 \mathrm{mg} / \mathrm{mL}]$.

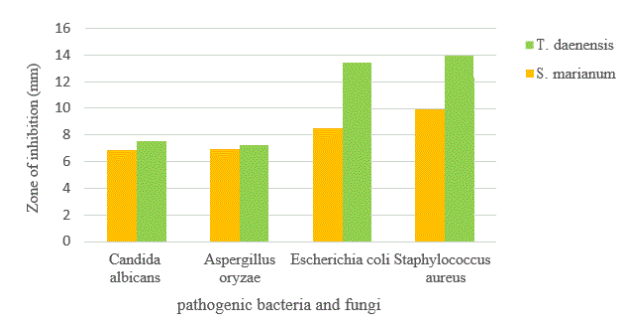

Figure 9: Antimicrobial activity of extracts $[12.5 \mathrm{mg} / \mathrm{mL}]$. 
Citation: Safarpoor M, Yousefinejad M, Ghaedi M, Zare Khafri H, Asfaram A, et al. (2017) Ultrasound-Assisted Extraction of Antimicrobial Compounds from Thymus daenensis and Silybum marianum and Investigation of its in Presence and Without of Natural Silver Nanoparticles. Nat Prod Chem Res 5: 289. doi:10.4172/2329-6836.1000289

Page 6 of 9

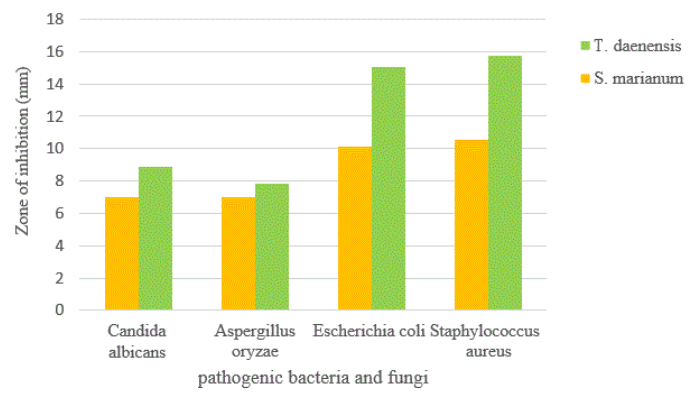

Figure 10: Antimicrobial activity of extracts [25 mg/mL].

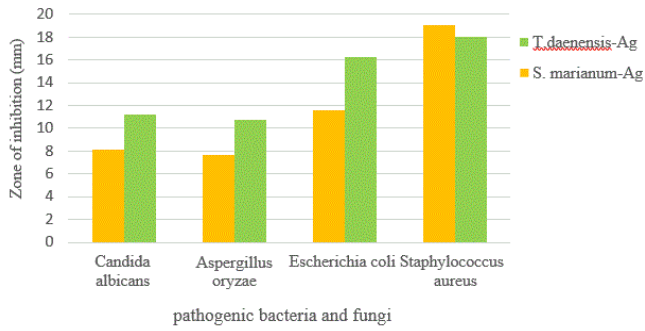

Figure 11: Antimicrobial activity of extracts in presence of natural silver nanoparticles $[25 \mathrm{mg} / \mathrm{mL}]$.

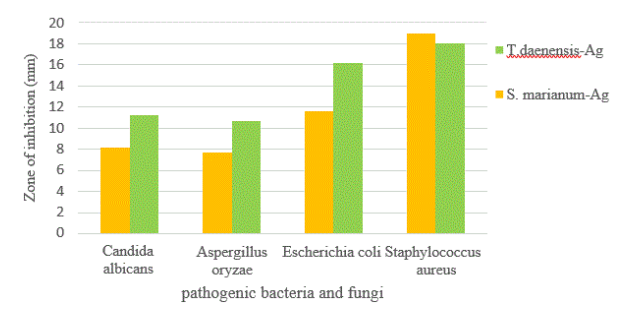

Figure 12: Antimicrobial activity of extracts $[50 \mathrm{mg} / \mathrm{mL}]$.

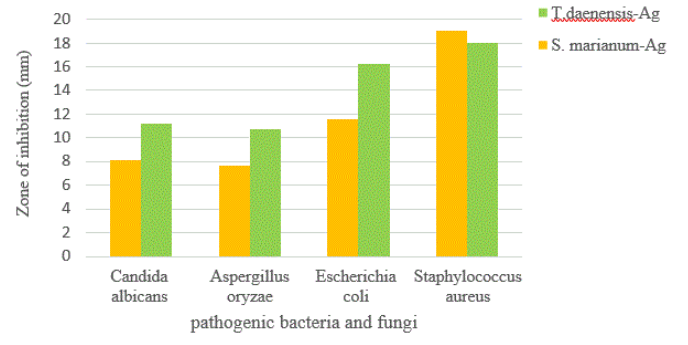

Figure 13: Antimicrobial activity of extracts in presence of natural silver nanoparticles $[50 \mathrm{mg} / \mathrm{mL}]$.

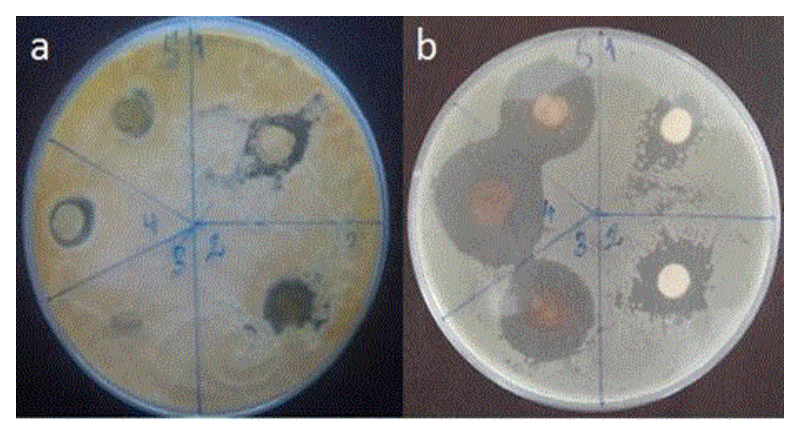

Figure 14: The inhibition halos for antifungal and (a) antibacterial activity (b) $\left(50 \mathrm{mg} \mathrm{L}^{-1}\right)$.

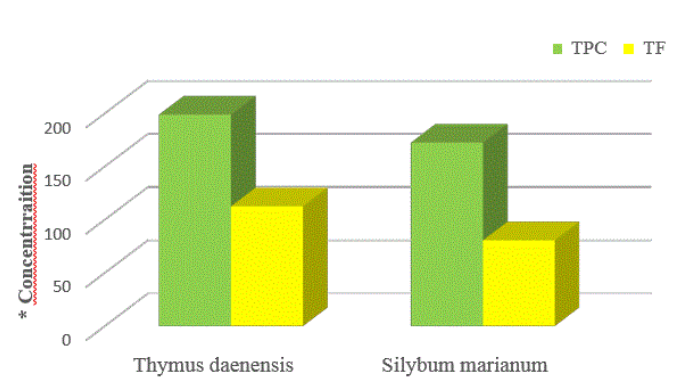

Figure 15: ${ }^{*}$ TPC: $\mathrm{mg}$ gallic acid equivalent/g of dried extract and TF: $\mathrm{mg}$ rutin equivalents $(\mathrm{RuE}) / \mathrm{g}$ of dried extract.

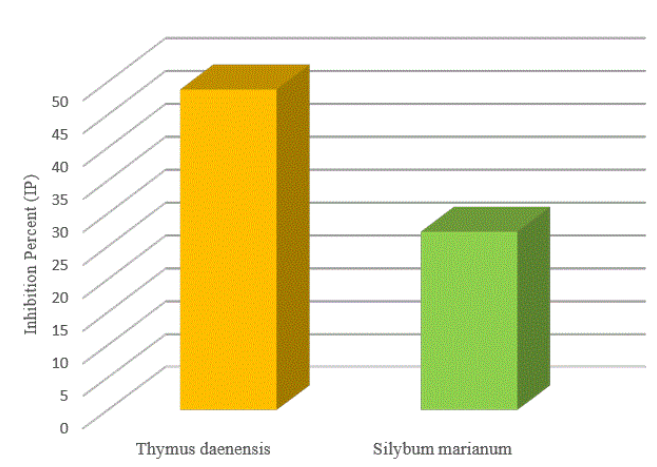

Figure 16: Comparison of inhibition percent.

Total flavonoids and phenolic content: Flavonoids are polyphenolic compounds which play an important role in stabilizing lipid oxidation and are also associated with antioxidative action [61]. Flavonoids found ubiquitously in plants and are the most common group of phytophenolics. Flavonoid content of the extracts in terms of $(\mathrm{mg} / \mathrm{g})$ rutin equivalents was recorded.

Phenols are the simplest bioactive phytochemicals having free radical scavenging ability due to the presence of hydroxyl groups. The sites and the numbers of hydroxyl groups are related to their relative toxicity for microorganisms, recently is shown that increasing in hydroxylation of these compounds cause to increasing in their toxicity properties [62]. The phenolic contents of hydroalcoholic extracts of 
Citation: Safarpoor M, Yousefinejad M, Ghaedi M, Zare Khafri H, Asfaram A, et al. (2017) Ultrasound-Assisted Extraction of Antimicrobial Compounds from Thymus daenensis and Silybum marianum and Investigation of its in Presence and Without of Natural Silver Nanoparticles. Nat Prod Chem Res 5: 289. doi:10.4172/2329-6836.1000289

Page 7 of 9

plants were tested using the diluted Folin-Ciocalteu reagent (FCR) Phenolic compounds react with FCR only under basic conditions (adjusted by a sodium carbonate solution to $\mathrm{pH}=10$ ). Dissociation of a phenolic proton leads to a phenolate anion, which is capable of reducing FCR. The reaction occurs through electron transfer mechanism. The blue compounds formed between phenolate and FCR are independent of the structure of phenolic compounds, therefore ruling out the possibility of coordination complexes formed between the metal center and the phenolic compounds. It is believed that FCR contains hetero polyphosphotunstates-molybdates [63]. The highest contents of total flavonoid and phenolics were observed for Shoot $L$. usitatissimum results clearly. (Table 4 and Figure 15).

\begin{tabular}{|l|l|l|l|}
\hline Extracts & TPC $^{\text {a }}$ & TF $^{\text {b }}$ & (DPPH) inhibition \% \\
\hline T. daenensis & $198.71 \pm 1.50$ & $172.42 \pm 1.43$ & $48.80 \pm 0.59$ \\
\hline S. marianum & $112.44 \pm 1.38$ & $80.50 \pm 1.41$ & $27.20 \pm 0.32$ \\
\hline aTPC: total phenolic content, mg gallic acid equivalent/g of dried extract & & \\
\hline bTF: total flavonoid content, mg rutin equivalents (RuE)/g of dried extract & & \\
\hline
\end{tabular}

Table 4: Total phenolic, flavonoid content and antioxidant activity of hydroalcoholy extracts.

\section{Antioxidant capacity}

Recently, using of antioxidants is proposed to protect people from oxidative stress damages. This study indicated that higher concentration of phenolic compounds in hydroalcoholic extracts improved antioxidant activity. Then these plants can be a use as a source of natural antioxidants to remove harmful effects of free radicals. The in-vitro antioxidant activity of test extracts were estimated by using of DPPH assay. DPPH radical-scavenging activity test measures the capacity of the extracts to scavenge the stable radical 2,2-diphenyl-1-picrylhydrazyl. If the extracts have this capacity, the initial blue/purple solution will change to a yellow color due to the formation of diphenyl picrylhydrazine. The antioxidants reacted with $\mathrm{DPPH}$, a purple coloured stable free radical which accepts an electron or hydrogen radical to become a stable diamagnetic molecule. The amount of DPPH reduced was estimated by measuring the decrease in absorbance at $517 \mathrm{~nm}$. The highest DPPH radical scavenging was obtained by aqueous/ethanolic extract of $T$. daenensis (Bois leaves $48.80 \pm 0.59 \%)$ Figure 15 results was showed in Table 4 . The different types of functional groups of extracts were identified from Figure 1 and Table 5.

\begin{tabular}{|l|l|l|l|}
\hline S. No & $\begin{array}{l}\text { Average } \\
\text { Peaks value }\end{array}$ & Stretching & Interpretation \\
\hline 1 & 423.37 & C-H bending outside of page & Alkanes \\
\hline 2 & 592.72 & C-O Stretching & Alcohols \\
\hline 3 & 1067.22 & O-H bending outside of page & Alcohols \\
\hline 4 & 1404.07 & C-H Bending & Alkanes \\
\hline 5 & 1625.78 & C=C Stretching & Alkenes \\
\hline 6 & 2932.12 & C-H Stretching & Alkanes \\
\hline 7 & 3398.62 & O-H Stretching & Alcohols \\
\hline
\end{tabular}

Table 5: Infrared spectrum analysis of extracts.

\section{Conclusion}

The antimicrobial activities of $T$. daenensis and $S$. marianum extracts and Ag-NPs/extracts assessed against pathogenic bacteria and fungi. Information of Tables of both samples was showed that biological Ag nanoparticle (Ag-NPs/T. daenensis and Ag-NPs/S. marianum) has more antimicrobial effects to extracts ( $T$. daenensis and $S$. marianum). Therefore, by completion of these experiments and the use of metal nanoparticles with plant extract in sensitive environments such as hospital, etc., suggested. Among the most promising nanomaterials with antibacterial properties are metallic nanoparticles, which exhibit increasing chemical activity due to their large surface to volume ratios and crystallographic surface structure. using of medicinal plant extracts with metal nanoparticles can be effective to eliminate the bacterial infections, as an alternative to antibiotics. $T$. daenensis and $S$. marianum are an abundant source of phenol and flavonoids, which have antioxidant properties and significantly reduce the effects of free radicals.

\section{Acknowledgment}

This work was supported by a grant from Research Council of Yasouj University.

\section{References}

1. Egger S, Lehmann RP, Height MJ, Loessner MJ, Schuppler M (2009) Antimicrobial properties of a novel silver-silica nanocomposite material. Appl Environ Microbiol 75: 2973-2976.

2. Bae E, Park HJ, Lee J, Kim Y, Yoon J, et al. (2010) Bacterial cytotoxicity of the silver nanoparticle related to physicochemical metrics and agglomeration properties. Environ Toxicol Chem 29: 2154-2160.

3. Gurunathan S, Kalishwaralal K, Vaidyanathan R, Venkataraman D, Pandian SR, et al. (2009) Biosynthesis, purification and characterization of silver nanoparticles using Escherichia coli. Coll Surf B: Biointer 74: 328-335.

4. Pal S, Tak YK, Song JM (2007) Does the antibacterial activity of silver nanoparticles depend on the shape of the nanoparticle? A study of the gram-negative bacterium Escherichia coli. Appl Environ Microbiol 73: 1712-1720.

5. Chen W, Cai W, Zhang L, Wang G, Zhang L, et al. (2001) Sonochemical processes and formation of gold nanoparticles within pores of mesoporous silica. J Coll Interf Sci 238: 291-295.

6. Ramajo L, Parra R, Reboredo M, Castro M (2009) Preparation of amine coated silver nanoparticles using triethylenetetramine. J Chem Sci 121: 83-87.

7. Taubner T, Hillenbrand R (2005) Nanoscale-resolved subsurface imaging by scattering-type near-field optical microscopy. Optics Exp 13: 8893-8899. 
Citation: Safarpoor M, Yousefinejad M, Ghaedi M, Zare Khafri H, Asfaram A, et al. (2017) Ultrasound-Assisted Extraction of Antimicrobial Compounds from Thymus daenensis and Silybum marianum and Investigation of its in Presence and Without of Natural Silver Nanoparticles. Nat Prod Chem Res 5: 289. doi:10.4172/2329-6836.1000289

Page 8 of 9

8. Zhang L, RadovicMoreno AF, Alexis F, Gu FX, Basto PA, et al. (2007) Codelivery of hydrophobic and hydrophilic drugs from nanoparticleaptamer bioconjugates. Chem Med Chem 2: 1268-1271.

9. Wiley B, Sun Y, Xia Y (2007) Synthesis of silver nanostructures with controlled shapes and properties. Acc Chem Res 40: 1067-1076.

10. Dwivedi P, Narvi SS, Tewari RP (2012) Green route to a novel Ag/PLGA bionanocomposite: A self-sterilizing surgical suture biomaterial. Int J Adv Eng Sci Technol 2: 236-243.

11. Shahverdi AR, Fakhimi A, Shahverdi HR, Minaian S (2007) Synthesis and effect of silver nanoparticles on the antibacterial activity of different antibiotics against Staphylococcus aureus and Escherichia coli. Nanomedicine: Nanotechn Biol Med 3: 168-1671.

12. Fayaz AM, Balaji K, Girilal M, Yadav R, Kalaichelvan PT, et al. (2010) Biogenic synthesis of silver nanoparticles and their synergistic effect with antibiotics: a study against gram-positive and gram-negative bacteria. Nanomedicine: Nanotechn Biol Med 6: 103-109.

13. Lara HH, Garza-Treviño EN, Ixtepan-Turrent L, Singh DK (2011) Silver nanoparticles are broad-spectrum bactericidal and virucidal compounds. J Nanobiotech 9: 30.

14. Illingworth B, Bianco RW, Weisberg S (2000) In vivo efficacy of silvercoated fabric against Staphylococcus epidermidis. J Heart Valve Dis 9: 135-1341.

15. Hoffmann S (1984) Silver sulfadiazine: an antibacterial agent for topical use in burns. Scandinavian J Plastic Reconstru Surg 18: 119-126.

16. Lara HH, Ayala-Nuñez NV, Ixtepan-Turrent L, Rodriguez-Padilla C (2010) Mode of antiviral action of silver nanoparticles against HIV-1. J Nanobiotechn 8: 1.

17. Petrus EM, Tinakumari S, Chai LC, Ubong A, Tunung R, et al. (2011) A study on the minimum inhibitory concentration and minimum bactericidal concentration of Nano Colloidal Silver on food-borne pathogens. Intern Food Res J 18: 15-60.

18. Saito K, Uemura E, Ishizaki A, Kataoka H (2010) Determination of perfluorooctanoic acid and perfluorooctane sulfonate by automated intube solid-phase microextraction coupled with liquid chromatographymass spectrometry. Analytica chimica acta 658: 141-146.

19. Prakash A, Sharma S, Ahmad N, Ghosh A, Sinha P (2011) Synthesis of AgNps By Bacillus cereus bacteria and their antimicrobial potential. J Biomat Nanobiotech 2: 156

20. Bjerrum L, Munck A, Gahrn-Hansen B, Hansen MP, Jarbol DE, et al. (2011) Health Alliance for prudent antibiotic prescribing in patients with respiratory tract infections (HAPPY AUDIT)-impact of a nonrandomised multifaceted intervention programme. BMC Fam Pract 12: 52 .

21. Premanath R, Lakshmi Devi N (2010) Studies on Anti-oxidant activity of Tinospora cordifolia (Miers.) Leaves using in vitro models. J Amer Sci 6: 10 .

22. KarabayYavasoglu NU, Sukatar A, Ozdemir G, Horzum Z (2007) Antimicrobial activity of volatile components and various extracts of the red alga Jania rubens. Phytotherapy Res 21: 153-156.

23. Mayer AM, Rodríguez AD, Berlinck RG, Hamann MT (2009) Marine pharmacology in 2005-2006: Marine compounds with anthelmintic, antibacterial, anticoagulant, antifungal, anti-inflammatory, antimalarial, antiprotozoal, antituberculosis, and antiviral activities; affecting the cardiovascular, immune and nervous systems, and other miscellaneous mechanisms of action. Biochimica et Biophysica Acta (BBA)-General Subjects 1790: 283-308.

24. Wang H, Provan GJ, Helliwell K (2004) Determination of rosmarinic acid and caffeic acid in aromatic herbs by HPLC. Food Chem 87: 307-311.

25. Vieira A (2010) A comparison of traditional anti-inflammation and antiinfection medicinal plants with current evidence from biomedical research: Results from a regional study. Pharmacog Res 2: 293.

26. Hajimehdipoor H, Shekarchi M, Khanavi M, Adib N, Amri M (2010) A validated high performance liquid chromatography method for the analysis of thymol and carvacrol in Thymus vulgaris L. volatile oil. Pharmacog Mag 6: 154
27. Zheng W, Wang SY (2001) Antioxidant activity and phenolic compounds in selected herbs. J Agricult Food chem 49: 5165-5170.

28. Ross R (1999) Atherosclerosis-an inflammatory disease. New England J Med 340: 115-126.

29. Ito H, Miyazaki T, Ono M, Sakurai H (1998) Antiallergic activities of rabdosiin and its related compounds: chemical and biochemical evaluations. Bioorg Medic Chem 6: 1051-1056.

30. Takeda H, Tsuji M, Matsumiya T, Kubo M (2002) Identification of rosmarinic acid as a novel antidepressive substance in the leaves of Perilla frutescens Britton var. acuta Kudo (Perillae Herba). Japanese J Psychopharmaco 22: 15-22.

31. Kumar PM, Sasmal D, Mazumder PM (2010) The antihyperglycemic effect of aerial parts of Salvia splendens (scarlet sage) in streptozotocininduced diabetic-rats. Pharmacog Res 2: 190.

32. Jain R, Kosta S, Tiwari A (2010) Ayurveda and urinary tract infections. J Young Pharmac 2: 337.

33. Zomorodian K, Saharkhiz MJ, Rahimi MJ, Bandegi A, Shekarkhar G, et al, (2011) Chemical composition and antimicrobial activities of the essential oils from three ecotypes of Zataria multiflora. Pharmacog Mag 7: 53 .

34. Ghorbani A (2005) Studies on pharmaceutical ethnobotany in the region of Turkmen Sahra, North of Iran:(Part 1): General results. J Ethnopharmacol 102: 58-68.

35. Djeridane A, Yousfi M, Nadjemi B, Boutassouna D, Stocker P, et al. (2006) Antioxidant activity of some Algerian medicinal plants extracts containing phenolic compounds. Food chem 97: 654-660.

36. Seyyednejad SM, Motamedi H (2010) A Review on native medicinal plants in Khuzestan, Iran with antibacterial properties. Intern J pharmacol 6: 551-560.

37. Bauer K, Garbe D, Surburg H (2008) Common fragrance and flavor materials: preparation, properties and uses. John Wiley and Sons.

38. Polyak SJ, Ferenci P, Pawlotsky JM (2013) Hepatoprotective and antiviral functions of silymarin components in hepatitis $\mathrm{C}$ virus infection. Hepatol 57: 1262-1271.

39. Polyak SJ, Oberlies NH, Pécheur EI, Dahari H, Ferenci P, et al. (2013) Silymarin for hepatitis C virus infection. Antiviral Therapy 18: 141.

40. Abenavoli L, Capasso R, Milic N, Capasso F (2010) Milk thistle in liver diseases: past, present, future. Phytother Res 24: 1423-1432.

41. Agarwal R, Agarwal C, Ichikawa H, Singh RP, Aggarwal BB (2006) Anticancer potential of silymarin: from bench to bed side. Anticancer Res 26: 4457-4498.

42. Deep G, Agarwal R (2010) Antimetastatic efficacy of silibinin: molecular mechanisms and therapeutic potential against cancer. Cancer Metast Rev 29: 447-463.

43. Ramasamy K, Agarwal R (2008) Multitargeted therapy of cancer by silymarin. Cancer Lett 269: 352-362.

44. Comelli MC, Mengs U, Schneider C, Prosdocimi M (2007) Toward the definition of the mechanism of action of silymarin: activities related to cellular protection from toxic damage induced by chemotherapy. Integra canc Therap 6: 120-129.

45. Gazak R, Walterova D, Kren V (2007) Silybin and silymarin-new and emerging applications in medicine. Curr Medic Chem 14: 315-338.

46. Cowan MM (1999) Plant products as antimicrobial agents. Clinic Microbiol Rev 12: 564-582.

47. Dahanukar SA, Kulkarni RA, Rege NN (2000) Pharmacology of medicinal plants and natural products. Indian J pharmacol 32: 81-118.

48. Gul HI, Sahin F, Gul M, Ozturk S, Yerdelen KO (2005) Evaluation of antimicrobial activities of several Mannich bases and their derivatives. Archiv der Pharmazie 338: 335-338.

49. Ramasamy S, Manoharan AC (2004) Antibacterial effect of volatile components of selected medicinal plants against human pathogens. Asian J Microbiol Biotech Environ Sci 6: 209-210.

50. Ensminger D, Bond LJ (2011) Ultrasonics: fundamentals, technologies and applications. CRC press. 
Citation: Safarpoor M, Yousefinejad M, Ghaedi M, Zare Khafri H, Asfaram A, et al. (2017) Ultrasound-Assisted Extraction of Antimicrobial Compounds from Thymus daenensis and Silybum marianum and Investigation of its in Presence and Without of Natural Silver Nanoparticles. Nat Prod Chem Res 5: 289. doi:10.4172/2329-6836.1000289

Page 9 of 9

51. Choudhury HA, Chakma S, Moholkar VS (2014) Mechanistic insight into sonochemical biodiesel synthesis using heterogeneous base catalyst. Ultrason Sonochem 21: 169-181.

52. Brakke MK (1961) Density gradient centrifugation and its application to plant viruses. Adv Virus Res 7: 193-224.

53. Jimenez VL, Leopold MC, Mazzitelli C, Jorgenson JW, Murray RW (2003) HPLC of monolayer-protected gold nanoclusters. Analy chem 75: 199-206.

54. Kowalczyk B, Lagzi I, Grzybowski BA (2011) Nanoseparations: strategies for size and/or shape-selective purification of nanoparticles. Current Opin Coll Interf Sci 16: 135-148.

55. Bauer AW, Kirby WM, Sherris JC, Turck M (1966) Antibiotic susceptibility testing by a standardized single disk method. Amer J clinic Pathol 45: 493.

56. Chohan ZH, Youssoufi MH, Jarrahpour A, Hadda TB (2010) Identification of antibacterial and antifungal pharmacophore sites for potent bacteria and fungi inhibition: Indolenyl sulfonamide derivatives. Europ J Medic Chem 45: 1189-1199.

57. McDonald S, Prenzler PD, Antolovich M, Robards K (2001) Phenolic content and antioxidant activity of olive extracts. Food chem 73: 73-84.
58. Zhishen J, Mengcheng T, Jianming W (1999) The determination of flavonoid contents in mulberry and their scavenging effects on superoxide radicals. Food chem 64: 555-559.

59. Von Gadow A, Joubert E, Hansmann CF (1997) Comparison of the antioxidant activity of aspalathin with that of other plant phenols of rooibos tea (Aspalathus linearis), $\alpha$-tocopherol, BHT, and BHA. J Agricult Food Chem 45: 632-638.

60. Xing GX, Li N, Wang T, Yao MY (2003) Advances in studies on flavonoids of licorice. China J Chinese Mat Med 28: 593-597.

61. Fujiki H, Yoshizawa S, Horiuchi T, Suganuma M, Yatsunami J, et al. (1992) Anticarcinogenic effects of (-)-epigallocatechin gallate. Prevent Med 21: 503-509.

62. Huang D, Ou B, Prior RL (2005) The chemistry behind antioxidant capacity assays. J Agricult Food Chem 53: 1841-1856.

63. Yamaguchi T, Takamura H, Matoba T, Terao J (1998) HPLC method for evaluation of the free radical-scavenging activity of foods by using 1,1diphenyl-2-picrylhydrazyl. Biosci Biotech Biochem 62: 1201-1204. 